\title{
Study on Time Characteristics of Coupling Discharge in Pulsed Laser Induced Double-TIG Welding
}

\section{Xinkun Xu}

Dalian University of Technology https://orcid.org/0000-0001-9026-5771

\section{Huanyu Yang}

Dalian University of Technology

Liming Liu ( $\square$ liulm@dlut.edu.cn )

Dalian University of Technology

\section{Research Article}

Keywords: Hybrid welding, Pulsed laser, Double-TIG, Coupling discharge, Keyhole behavior, Time characteristics

Posted Date: August 13th, 2021

DOl: https://doi.org/10.21203/rs.3.rs-796847/v1

License: (c) (i) This work is licensed under a Creative Commons Attribution 4.0 International License. Read Full License 


\title{
Study on Time Characteristics of Coupling Discharge in Pulsed Laser Induced Double-TIG Welding
}

\author{
Xinkun Xu (徐信坤), Huanyu Yang (杨环宇), Liming Liu (刘黎明) \\ Key Laboratory of Liaoning Advanced Welding and Joining Technology, School of Materials Science and \\ Engineering, Dalian University of Technology, Dalian, 116024, China. \\ Corresponding Author / E-mail: liulm@dlut.edu.cn, TEL: +86-411-8470 7817, FAX: +86-411-8470 7817
}

\begin{abstract}
Based on the dynamic behavior of laser keyhole, the time characteristics of coupling discharge of heat source in pulsed laser induced double-TIG welding (LIDTW) are studied. The behaviors of arc plasma and laser keyhole were directly observed by high-speed camera and auxiliary illumination source. The physical characteristics of arc plasma were analyzed by spectrometer and arc quality analyzer. A physical model is established to reveal the regulation mechanism of time characteristics of coupling discharge. It is found that after laser pulse action the coupling discharge between keyhole plasma and double-arc plasma does not end immediately, and its time depends on the existence time of keyhole. During hybrid welding, when the combined force of arc pressure and Marangoni force can overcome the gravity, the liquid metal is forced out of the keyhole and the keyhole remains open. Improving the electron density of arc plasma and arc voltage and reducing the diameter of arc conductive channel by selecting appropriate parameters to is the key to prolong the existence time of keyhole, which is beneficial to improve the welding penetration. The coupling enhancement of double-arc electromagnetic field in LIDTW can effectively suppress keyhole backfill and increase the duty ratio of coupling discharge. When the total current intensity is $200 \mathrm{~A}$, compared with laser induced single-TIG welding (LISTW), the existence time of keyhole in LIDTW increases by $77 \%$, the duty ratio of coupling discharge increases by $12 \%$, and the weld penetration increases by $29.2 \%$.
\end{abstract}

Keywords: Hybrid welding; Pulsed laser; Double-TIG; Coupling discharge; Keyhole behavior; Time characteristics.

\section{Introduction}

High-efficiency and high-quality welding is the ultimate goal of welding technology development. Laser-arc hybrid welding first appeared in Germany in 1979. Because it uses the advantages of laser welding and arc welding to make up for the shortcomings of the two, it has the advantages of greater penetration and better bridging than single heat source welding. It has been rapidly developed and applied, and has developed a variety of typical combination forms of laser and single heat source: laser-TIG welding, laser-plasma arc welding, laser-MIG, etc[14].

In recent years, with the development of aerospace, petrochemical and automotive industry, higher requirements for welding efficiency have been put forward. Based on the double-arc heat source which can greatly improve the welding speed and cladding efficiency, the laser-double arc hybrid welding method has been developed and a lot of researches have been done[5-7]. In this hybrid welding method, double-arc is generated on two insulated electrodes and acts with laser beam in the same molten pool. Three heat sources interact to form a single highintensity energy source. According to the existing reports, the synergy of three heat sources in laser-double arc hybrid welding can obtain smaller welding heat input per unit length, and improve welding speed and penetration[8]. By analyzing the driving force in the weld pool, it is found that the laser-double arc hybrid welding process is conducive to the formation of uniform alloy element distribution and weld metal structure[9]. The interaction 
between laser and double-arc has also been studied. When the electromagnetic force of the two arcs to the laser plasma is equal, the lower position on both sides of the laser plasma has higher electron density, the arc will not deviate, and the stable droplet transfer without spatter can be realized[10]. Laser provides a stable plasma conductive channel for double-arc, which will influence the shape of arc plasma, slow down the speed of droplet transfer and stabilize arc discharge[11]. Compared with laser-single arc hybrid welding, the coupling mechanism of laser-double arc hybrid welding is more complex, which limits its development. Researchers have noticed that the coupling discharge between laser and arc is an important physical feature of hybrid heat source. In hybrid welding, the metal atoms of the workpiece migrate to the arc column to replace part of the gas atoms (such as argon atoms) to ionize and conduct electricity, which essentially changes the characteristics of the plasma (particle composition, ionization degree, electron temperature and density, etc.), and improves the energy density of the heat source, welding efficiency and stability[12-14]. As a form of energy distribution of welding heat source, the change of its coupling discharge characteristics will directly lead to the change of heating capacity and manufacturing results, which is also directly related to the production of welding industry. However, the relationship between the coupling discharge characteristics of heat source and welding parameters and its regulation mechanism have not been revealed. In order to deeply understand the coupling discharge behavior of laser induced double-arc welding, it is necessary to study the coupling discharge characteristics in hybrid welding process.

Due to the characteristics of low melting point, low boiling point and low ionization energy of magnesium alloy[15], the experimental phenomenon of laser induced arc discharge is amplified, which is conducive to the observation of the experimental results. Therefore, the welding experiments were selected on magnesium alloy. In this study, the effect of welding parameters on the time characteristics of coupling discharge of heat source was studied by monitoring keyhole behavior during and after laser pulse. The physical characteristics of plasma were analyzed by spectrometer and arc quality analyzer, and the physical model was established to reveal the regulation mechanism of time characteristics of coupling discharge. This research is of great significance to promote the development of laser induced double-arc welding technology.

\section{MATERIALS AND METHODS}

As shown in Fig. 1, the laser induced single/double-TIG welding system consists of a low power pulsed Nd: YAG laser power supply and one or two independent OTC AEP-500P TIG welding power supplies. The wavelength of the laser beam is $1064 \mathrm{~nm}$, and a circular spot with a diameter of $0.6 \mathrm{~mm}$ is focused on the workpiece by a convex lens with a focal length of $150 \mathrm{~mm}$. Laser beam is perpendicular to the surface of the workpiece. The rated average power of the laser is $1000 \mathrm{~W}$, and the pulse energy is controlled by the excitation current and pulse width of the pulsed laser. During laser induced double-TIG welding (LIDTW), double-arc is generated by two TIG welding torches which are close to each other. The welding torches are respectively equipped with specially processed ceramic nozzles to ensure that the distance between two tungsten electrode tip (Daa) can be adjusted freely. Two TIG welding torches are placed on the same side of the laser beam and symmetrically distributed on the X-Z plane where the laser beam axis is. The angle between welding torches is about $15^{\circ}$, the angle between the torch and the workpiece about $45^{\circ}$. The relative position of laser beam and double-arc on the workpiece is determined by Daa and horizontal distance between the tungsten electrode tip and laser beam axis (Dla), and these two parameters can be adjusted respectively by the micrometer translation stage, realizing the paraxial hybrid of arc and laser. During laser induced single-TIG welding (LISTW), the welding torch and laser beam are in the same plane and the torch keep the angle of $45^{\circ}$ with the laser beam. Argon with the purity of $99.99 \%$ is used as protecting gas, and the flow rate of protecting gas through the torch nozzle is set as $12 \mathrm{~L} / \mathrm{min}$. The height of tungsten electrode is set to $2 \mathrm{~mm}$.

In order to observe the arc plasma and keyhole behavior in the hybrid welding process, a high-speed camera and auxiliary lighting source are used to monitor the welding arc and the surface of the molten pool, as shown in 
Fig. 1. A narrow-band filter with a central wavelength of $809.5 \mathrm{~nm}$ and full width at half maximum $9.2 \mathrm{~nm}$ is installed in front of the high-speed camera lens to monitor the dynamic behavior of $\mathrm{Ar}$ arc plasma. The diode laser generator with a wavelength of $808 \mathrm{~nm}$ and an output power of $0-40 \mathrm{~W}$ is used to illuminate the surface of the workpiece to form a circular bright area with a diameter of $30 \mathrm{~mm}$, which is sufficient to cover the entire welding pool. The maximum power density of the circular spot is approximately $5.66 \mathrm{~W} / \mathrm{cm}^{2}$. The high-speed camera can capture the reflected light on the surface of the weld pool, so as to obtain the information about the behavior of the weld pool. The acquisition frequency of the camera is set to 2500 frames/s.

The SP-2556 emission spectrometer manufactured by Princeton Company was used to collect spectral information of arc plasma in the welding process, as shown in Fig. 1. The optical fiber probe transmits the acquired plasma optical emission signal to the spectrometer. Under the transformation of computer software (WinSpec/32), the intensity - wavelength curve is formed. The spectral information in the hybrid welding process is shown in Fig. 2 , and the acquiring position is shown in Fig. 1. In order to reduce the error, the temperature of the vacuum chamber inside the spectrometer was cooled to $-70^{\circ} \mathrm{C}$ before data collection. The wavelength range, exposure time and resolution of spectral information acquisition can be set by computer software. In this study, a 300 grove $/ \mathrm{mm}$ grating with a resolution of $0.128 \mathrm{~nm}$ was used to collect the spectral information of the arc plasma within the wavelength range of $200 \mathrm{~nm}$ to $1000 \mathrm{~nm}$, which was used to calculate the electron temperature. A 2400 grove $/ \mathrm{mm}$ grating with a resolution of $0.011 \mathrm{~nm}$ was used to collect the information of a single spectral line and calculate the electron density of the arc plasma. The exposure time and data readout time are set to $20 \mathrm{~ms}$ and $13.4 \mathrm{~ms}$ respectively.

Since the arc plasma is optical thin and satisfies the local thermodynamic equilibrium (LTE), the Boltzmann plot method can be used to calculate the electron temperature of the arc plasma [16]. In order to improve the accuracy of the estimation, the selection of spectral lines should follow the following criteria when calculating the electron temperature[17]:

$$
E_{1}-E_{2}>k T_{\mathrm{e}}
$$

Where $E$ is the upper level energy of the spectral lines, $k$ is the Boltzmann constant, $T_{\mathrm{e}}$ is the electron temperature of the plasma.

In this paper, three spectral lines with wavelengths of Mg I 470.299nm, Mg I 516.732nm and Mg I 552.84nm are selected to estimate the electron temperature $\left(T_{\mathrm{e}}\right)$ of the plasma. The physical parameters of plasma spectral lines can be found from NIST (National Institute of Standards and Technology) database [18].The spectral intensity could be obtained by the spectrograph. In the diagnosis of plasma with electron density greater than $10^{16} \mathrm{~cm}^{-3}$, the Stark broadening is the main factor affecting the spectral line profile [19], and the detailed calculation method of electron density can be found in [16]. The assumptions, calculation methods, check methods for LTE and optical thin of the welding plasma can be found in references [20].

The Hannover Arc Quality Analyzer (AH19) was used to collect the arc voltage under different welding parameters. The arc voltage signal is transmitted to the signal receiving device through the Hall sensor, and collected by the data acquisition card in the computer.

The experiment was carried out at atmospheric pressure and room temperature. The $6 \mathrm{~mm} \mathrm{AZ31B} \mathrm{Mg}$ alloy plate is used as the welding workpiece, and the chemical composition of Mg alloy is shown in Table 1. After welding, the weld joints were obtained perpendicular to the welding direction, and the etching test of the joint was carried out with acid solution $(5 \% \mathrm{HCl}+95 \%$ alcohol $)$ to observe the cross-section morphology of the joints. 


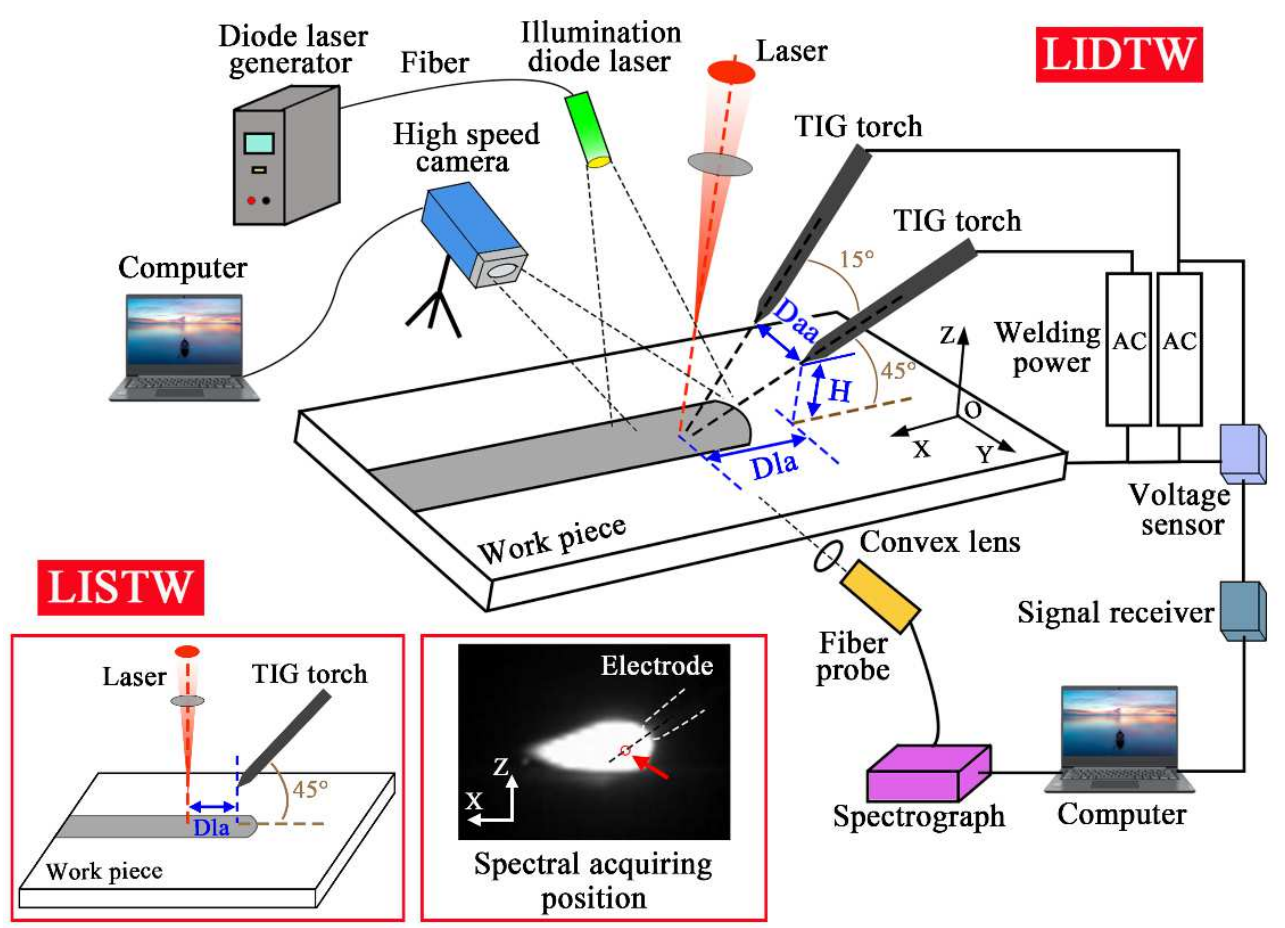

Fig. 1 Laser induced single/double-TIG welding and diagnosis system.

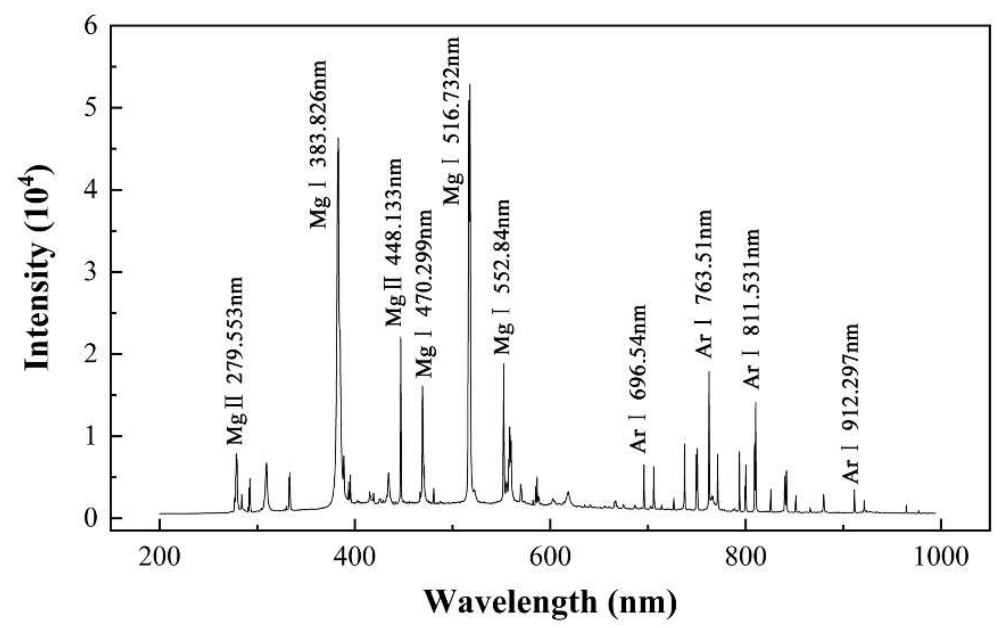

Fig. 2 Hybrid welding spectrum from $200 \mathrm{~nm}$ to $1000 \mathrm{~nm}$.

Table 1. Chemical composition (wt \%) of AZ31B Mg alloy.

\begin{tabular}{ccccccc}
\hline Alloy & $\mathrm{Al}$ & $\mathrm{Zn}$ & $\mathrm{Mn}$ & $\mathrm{Si}$ & $\mathrm{Cu}$ & $\mathrm{Mg}$ \\
\hline AZ31B & $2.5 \sim 3.5$ & $0.7 \sim 1.3$ & $0.2 \sim 1.0$ & $<0.05$ & $<0.01$ & Bal. \\
\hline
\end{tabular}

\section{Results}

3.1 Time characteristics of coupling discharge

The details of weld pool, keyhole and arc discharge under different welding processes (LISTW and LIDTW) can be observed synchronously by adjusting camera parameters (exposure time, grain value) and light source irradiation angle, as shown in Fig. 3. It can be seen from the figure that a small hole is formed on the surface of the molten pool by the action of laser pulse in hybrid welding. The keyhole plasma with low energy barrier can induce 
the arc plasma to discharge into the keyhole, thus forming a compressed conductive channel. As shown in Fig. 4, the keyhole does not disappear immediately after the laser pulse is over. It can be seen from the figure that when the single arc current is 100 A (LISTW $100 \mathrm{~A}$ ), the keyhole exists for $11.6 \mathrm{~ms}$, the surface of the molten pool is not smooth at all, and the wrinkles caused by the violent fluctuation of liquid metal can be observed. When the total current is $200 \mathrm{~A}$, the keyholes of LISTW $200 \mathrm{~A}$ and LIDTW $100+100$ A exist for $5.2 \mathrm{~ms}$ and $9.2 \mathrm{~ms}$ respectively, and the surface of molten pool becomes relatively smooth. Liquid wrinkles are only observed near the keyhole exit. After a period of time, liquid metal backfill, and keyhole disappeared. This phenomenon is called delayed closure of laser keyhole. This phenomenon is beneficial to prolong the duration of induced discharge effect and maintain the coupling discharge state of arc. In a laser pulse period, the arc discharge process can be divided into two stages: coupling discharge and arc free discharge.

Fig. 5 shows the time effect of coupling discharge in a single pulse period. It can be seen from the figure that the laser pulse frequency $(f)$ can control the laser pulse period $(T)$; The existence time of keyhole can control the coupling discharge period, so that the coupling discharge effect of heat source can be controlled in time scale. The time from keyhole formation to complete disappearance is defined as the coupling discharge period $\left(t_{\mathrm{c}}\right)$. The duty ratio of coupling discharge $(\varphi)$ is calculated by the ratio of the period of coupling discharge to the period of single pulse. $\varphi$ can describe the time characteristics of coupling arc heating weld pool, as shown in Formula 2:

$$
\varphi=\frac{t_{\mathrm{c}}}{T}=\frac{t_{\mathrm{c}} \times f}{1000} \times 100 \%
$$

It should be noted that the frequency of laser pulse is $30 \mathrm{~Hz}$ during the welding test, the welding process of each weld seam takes about $12 \mathrm{~s}$, and the number of laser pulses is extremely large. Therefore, when $t_{\mathrm{c}}$ is counted, 20 laser pulse periods are randomly selected for statistics and the average value is taken. The time characteristics and welding effect of coupling discharge under different welding processes are shown in Fig. 6. $\varphi$ of LISTW 100 $\mathrm{A}$ is $34.8 \%$, and the weld penetration is $3.36 \mathrm{~mm}$. Compared with LISTW 100A, $\varphi$ of LISTW 200A and LIDTW $100+100 \mathrm{~A}$ is reduced to $15.6 \%$ and $27.6 \%$ respectively. It is worth mentioning that $t_{\mathrm{c}}$ of LIDTW $100+100 \mathrm{~A}$ is $4 \mathrm{~ms}$ longer than that of LISTW $200 \mathrm{~A}$, and the weld penetration is increased from $4.39 \mathrm{~mm}$ to $5.67 \mathrm{~mm}$, which is $29.2 \%$ higher than that of LISTW $200 \mathrm{~A}$. It shows that prolonging the coupling discharge period and increasing the duty ratio of coupling discharge can increase the welding penetration and improve the welding efficiency.

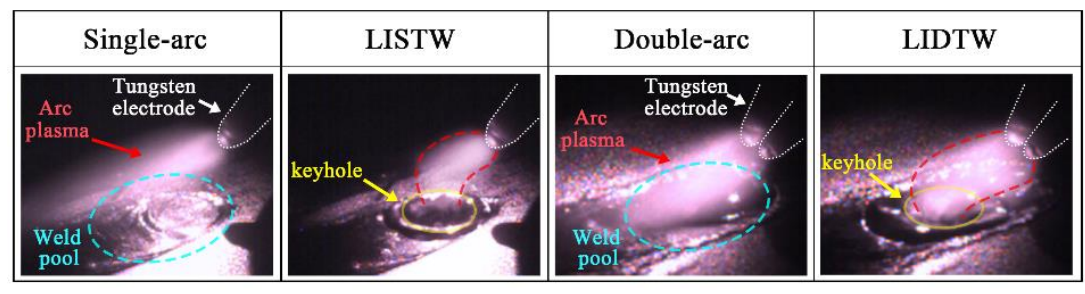

Fig. 3 Details of laser keyhole formation and arc plasma discharge.

Parameters: laser pulse energy $15 \mathrm{~J}$, pulse frequency $30 \mathrm{~Hz}$, pulse width $2.4 \mathrm{~ms}$, Dla $3.0 \mathrm{~mm}$, Daa $1.0 \mathrm{~mm}$, arc current: LISTW 100 A and LIDTW 100+100 A, welding speed 800 mm/min. 
(a)

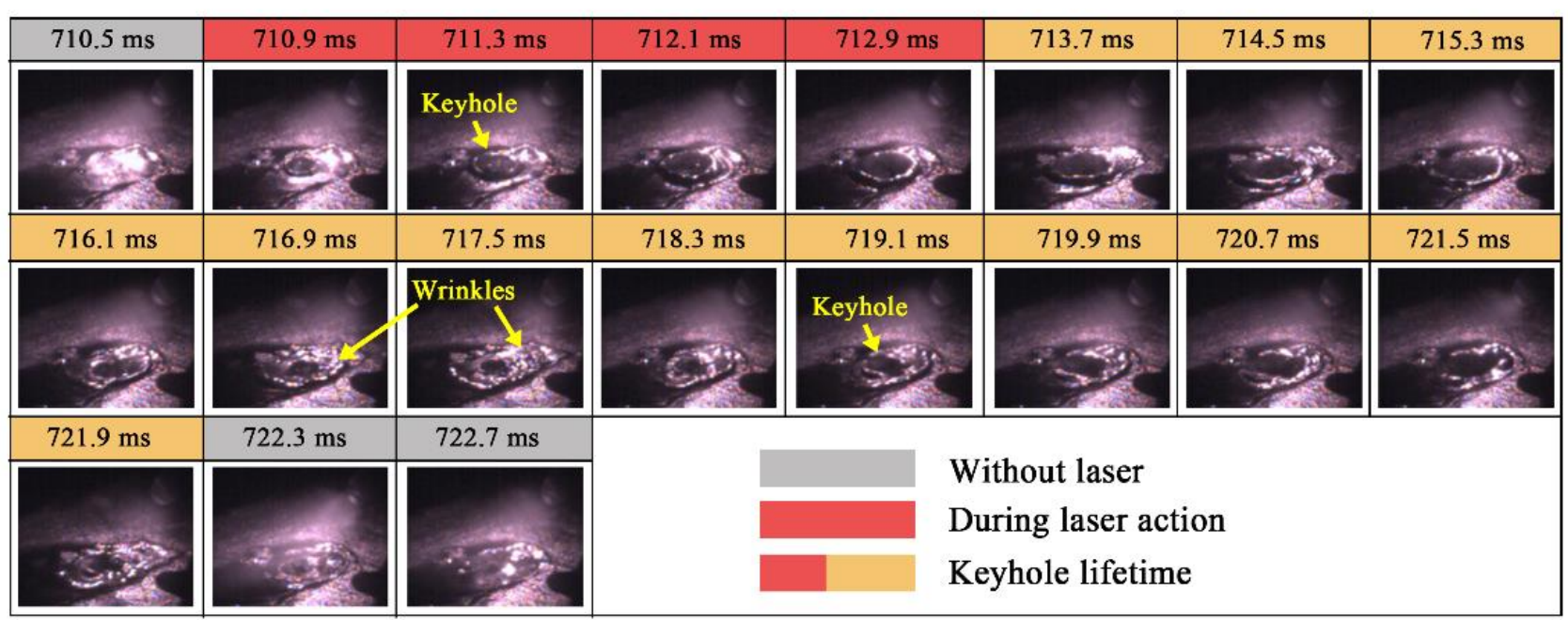

(b)

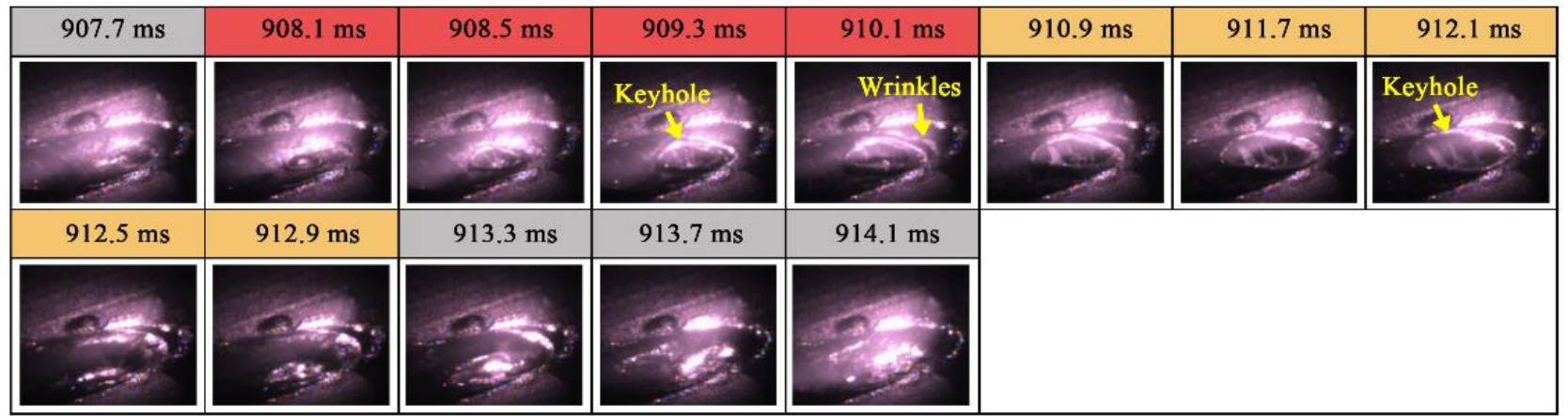

(c)

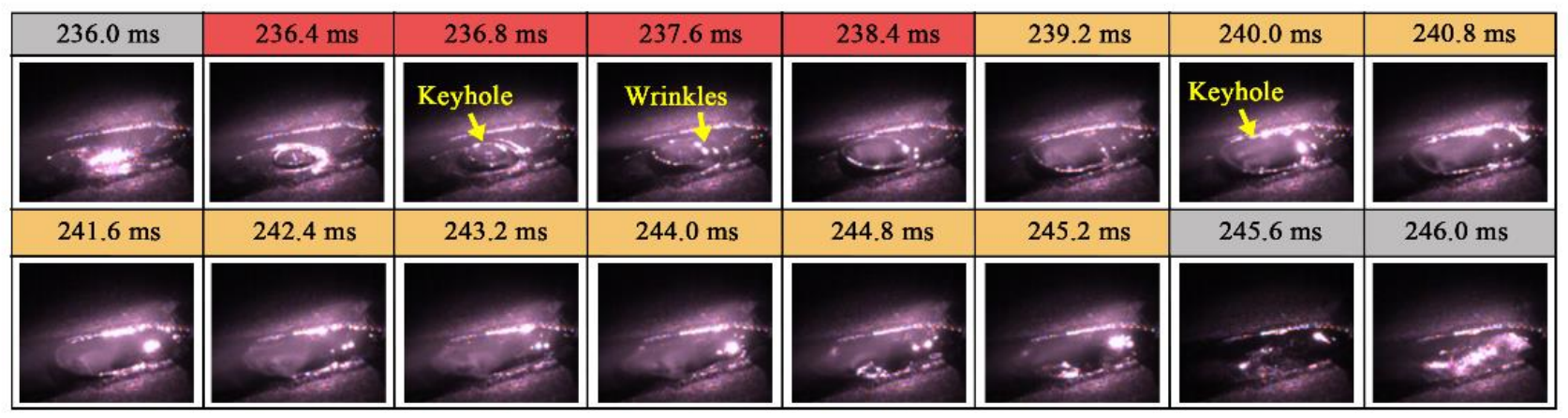

Fig. 4 Dynamic behavior of laser keyhole.

Parameters: laser pulse energy $15 \mathrm{~J}$, pulse frequency $30 \mathrm{~Hz}$, pulse width $2.4 \mathrm{~ms}$, Dla $3.0 \mathrm{~mm}$, Daa $1.0 \mathrm{~mm}$, arc current: (a) LISTW 100 A (b) LISTW 200 A (c) LIDTW 100+100 A, welding speed $800 \mathrm{~mm} / \mathrm{min}$.

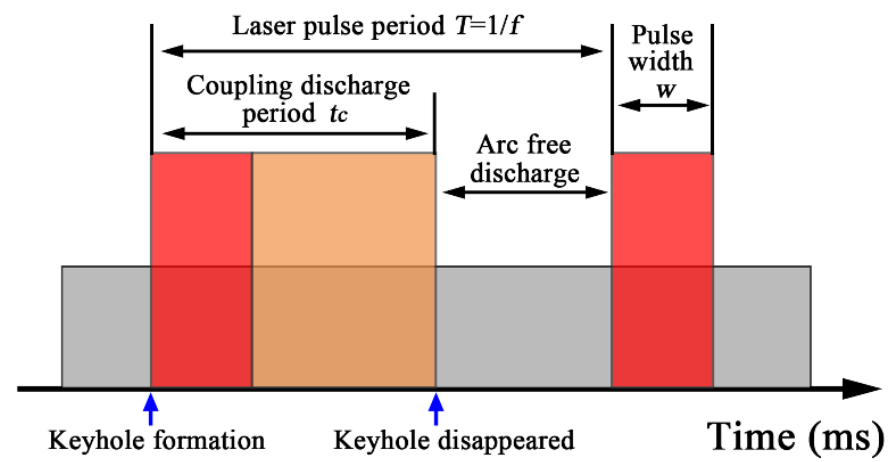

Fig. 5 Time effect diagram of coupling discharge in single pulse period. 


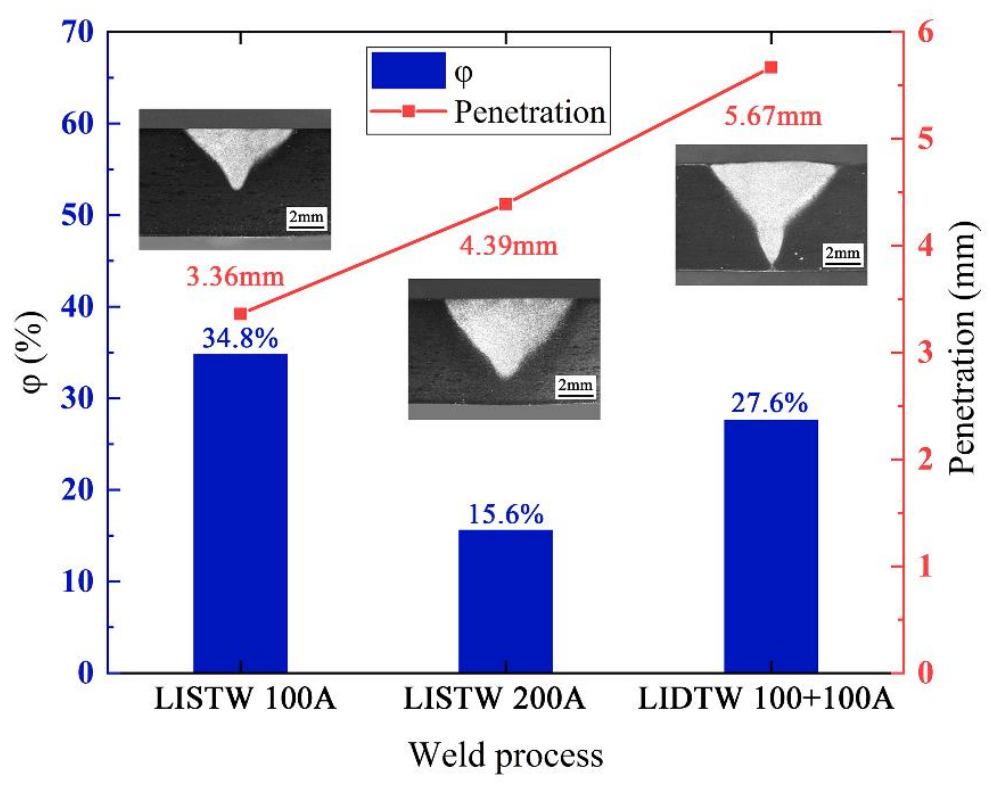

Fig. 6 Time characteristics of coupling discharge and weld penetration under different welding processes.

\subsection{Influence of parameters on time characteristics of coupling discharge}

\subsubsection{Arc current intensity}

Adjusting different arc current intensity for hybrid welding experiments, in order to control the state of the molten pool formed by the arc plasma before the laser pulse action, the research results on the time characteristics of the coupling discharge are shown in Fig. 7. It can be seen from the figure that as the total current intensity increases from $140 \mathrm{~A}$ to $220 \mathrm{~A}, t_{\mathrm{c}}$ of LISTW is shortened from $8.8 \mathrm{~ms}$ to $3.6 \mathrm{~ms}$, and $\varphi$ is reduced from $26.4 \%$ to $10.8 \%, t_{\mathrm{c}}$ of LIDTW is shortened from $15.6 \mathrm{~ms}$ to $7.6 \mathrm{~ms}, \varphi$ is reduced from $46.8 \%$ to $22.8 \%$. And under the condition of the same total current intensity, $\varphi$ of LIDTW is higher than that of LISTW. This difference means that there is an important relationship between different welding states (molten pool flow, plasma interaction, etc.) caused by the number of electrodes and keyhole behavior.
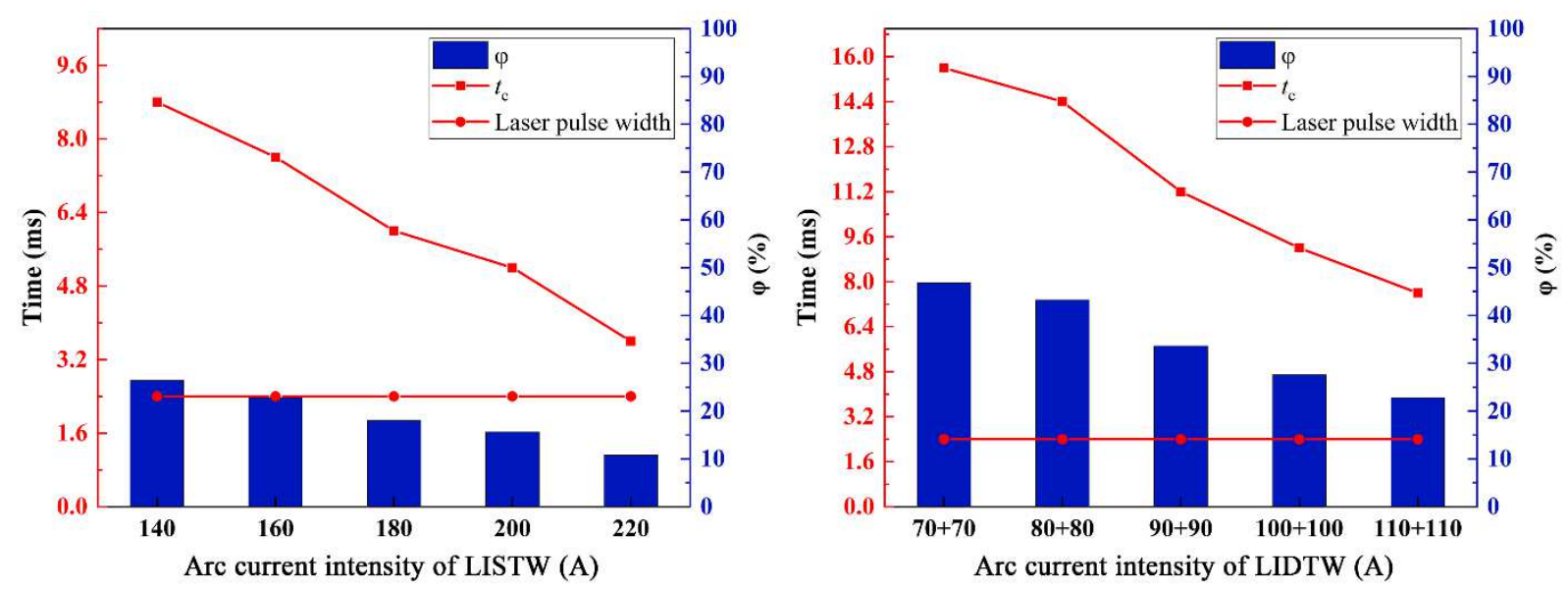

Fig. 7 Time characteristics of coupling discharge under different current intensity.

Parameters: laser pulse energy $15 \mathrm{~J}$, pulse frequency $30 \mathrm{~Hz}$, pulse width $2.4 \mathrm{~ms}$, Dla $3.0 \mathrm{~mm}$, Daa $1.0 \mathrm{~mm}$, welding speed $800 \mathrm{~mm} / \mathrm{min}$. 


\subsubsection{Laser pulse energy}

Fig. 8 and 9 show the relationship between the laser pulse energy and the time characteristics of the coupling discharge. It can be seen from Fig. 8 that when the laser pulse width remains unchanged, with the increase of laser pulse energy from $4 \mathrm{~J}$ to $16 \mathrm{~J}, t_{\mathrm{c}}$ of LISTW increases from $2.8 \mathrm{~ms}$ to $5.2 \mathrm{~ms}, \varphi$ increases from $8.4 \%$ to $15.6 \%, t_{\mathrm{c}}$ of LIDTW increases from $4.4 \mathrm{~ms}$ to $9.6 \mathrm{~ms}$, and $\varphi$ increases from $13.2 \%$ to $28.8 \%$. When the laser pulse energy increases by increasing the pulse width, a similar rule appears, as shown in Fig. 9.
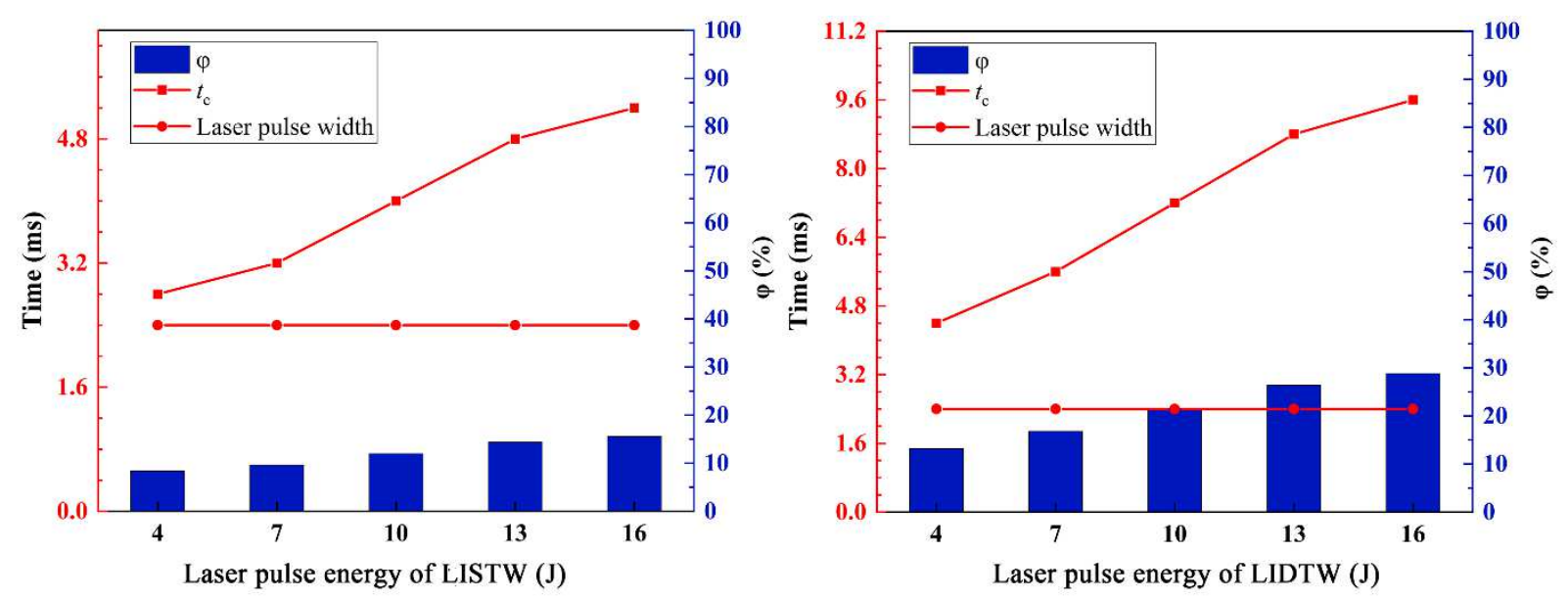

Fig. 8 Time characteristics of coupling discharge under different laser pulse energy (constant pulse width $2.4 \mathrm{~ms}$ ).

Parameters: laser pulse frequency $30 \mathrm{~Hz}$, Dla $3.0 \mathrm{~mm}$, Daa $1.0 \mathrm{~mm}$, arc current: LISTW $200 \mathrm{~A}$ and LIDTW 100+100 A, welding speed $800 \mathrm{~mm} / \mathrm{min}$.
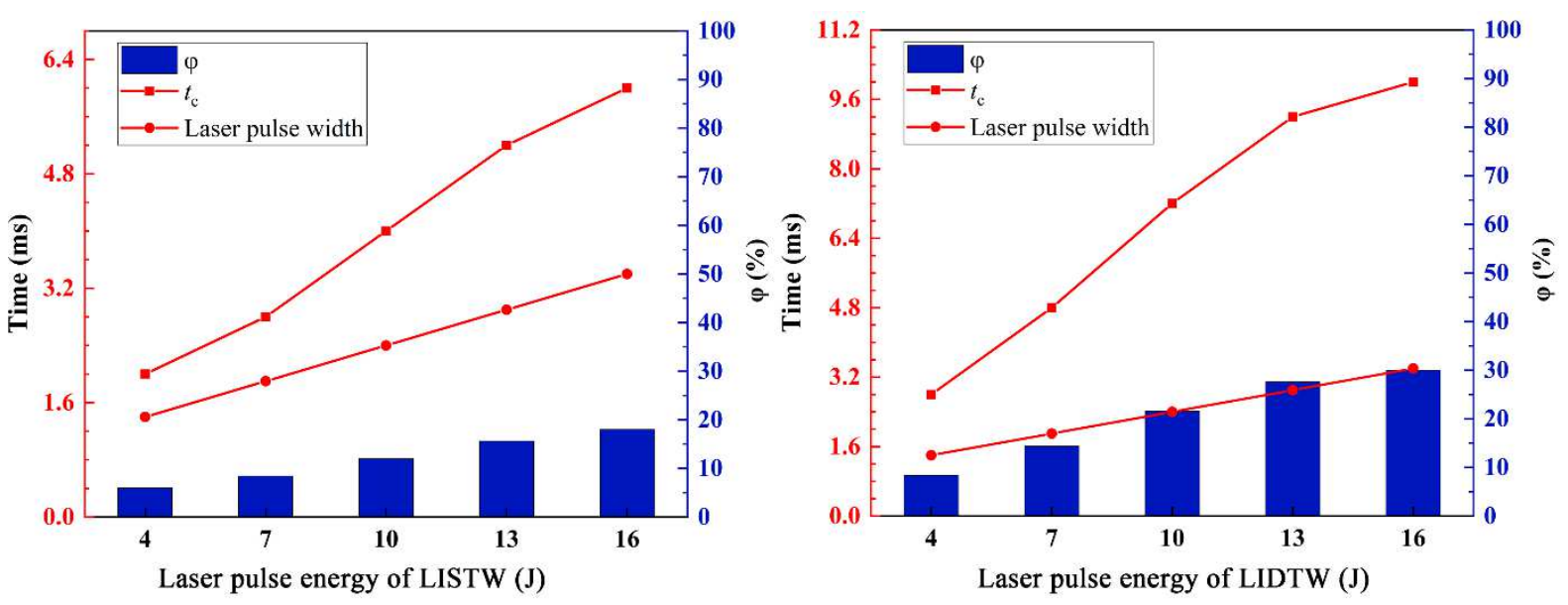

Fig. 9 Time characteristics of coupling discharge under different laser pulse energy.

(varying pulse width 1.4-3.4 ms) Parameters: laser pulse frequency $30 \mathrm{~Hz}$, Dla $3.0 \mathrm{~mm}$, Daa $1.0 \mathrm{~mm}$, arc current: LISTW 200 A and LIDTW 100+100 A, welding speed $800 \mathrm{~mm} / \mathrm{min}$.

\subsubsection{Daa}

Daa is a very significant parameter in LIDTW welding process, which can affect the coupling discharge behavior by changing the induced driving force of the laser on the $\operatorname{arc}[20]$. Therefore, the time characteristics of coupling discharge under different Daa are studied, as shown in Fig. 10. It can be seen from the figure that with the increase of Daa from $1 \mathrm{~mm}$ to $4 \mathrm{~mm}, t_{\mathrm{c}}$ of LIDTW is shortened from $9.2 \mathrm{~ms}$ to $2.4 \mathrm{~ms}$, and $\varphi$ is reduced from 
$27.6 \%$ to $7.2 \%$. When Daa is $4 \mathrm{~mm}, t_{c}$ of LIDTW coincides with the laser pulse width (2.4ms). It can be seen from Fig. 11 that when Daa is large enough (in this case, Daa is $4 \mathrm{~mm}$ ), the arc plasma obviously does not form an compressed conductive channel during the laser pulse action, and the keyhole is backfilled immediately after the laser action. The delayed closure of laser keyhole does not occur. In addition, compared with LISTW and LIDTW, it can be found that when Daa is small (Daa $=1,2 \mathrm{~mm}$ ), $\varphi$ of LIDTW is significantly higher than that of LISTW. When Daa increases to $3 \mathrm{~mm}, \varphi$ of LIDTW decreases to $12 \%$, which is lower than $15.6 \%$ of LISTW.

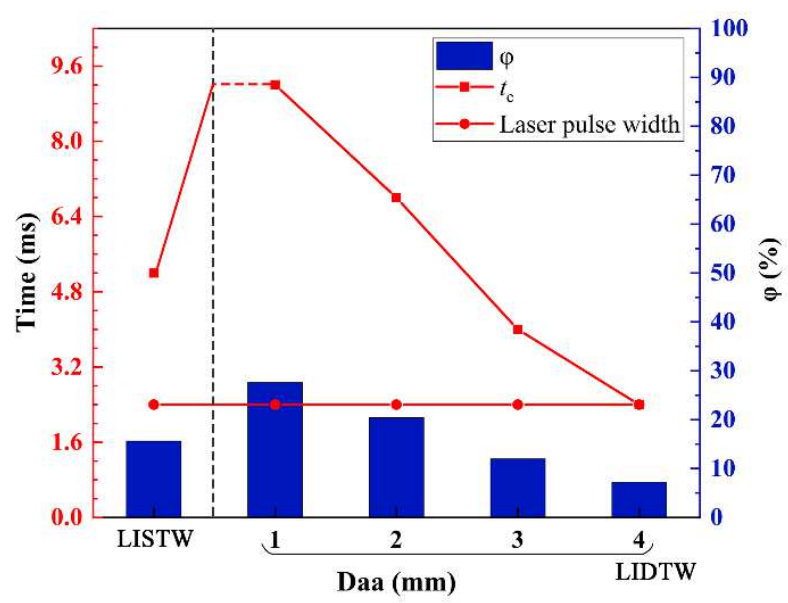

Fig. 10 Time characteristics of coupling discharge under different Daa.

Parameters: laser pulse energy $15 \mathrm{~J}$, pulse frequency $30 \mathrm{~Hz}$, pulse width $2.4 \mathrm{~ms}$, Dla $3.0 \mathrm{~mm}$, arc current: LISTW 200 A and LIDTW 100+100 A, welding speed $800 \mathrm{~mm} / \mathrm{min}$.

\begin{tabular}{|c|c|c|c|c|c|c|c|}
\hline $130.3 \mathrm{~ms}$ & $130.7 \mathrm{~ms}$ & $131.1 \mathrm{~ms}$ & $131.5 \mathrm{~ms}$ & $131.9 \mathrm{~ms}$ & $132.3 \mathrm{~ms}$ & $132.7 \mathrm{~ms}$ & $133.1 \mathrm{~ms}$ \\
\hline$\overline{\text { Arc plasma }}$ & & & Irc plasma & Electrode & & $\overline{\text { Arc plasma }}$ & \\
\hline $133.5 \mathrm{~ms}$ & $133.9 \mathrm{~ms}$ & $134.3 \mathrm{~ms}$ & $134.7 \mathrm{~ms}$ & $135.1 \mathrm{~ms}$ & $135.5 \mathrm{~ms}$ & \multirow{2}{*}{\multicolumn{2}{|c|}{$\begin{array}{l}\text { Without laser } \\
\text { During laser action }\end{array}$}} \\
\hline & & & & & & & \\
\hline
\end{tabular}

Fig. 11 Behavior of laser keyhole and arc plasma at Daa $4 \mathrm{~mm}$.

\subsection{Physical characteristics of arc plasma}

The dynamic behavior of arc plasma and laser keyhole is the external performance of welding which is related to the physical characteristics such as electron temperature, electron density and arc voltage. The physical characteristics of arc plasma under different welding parameters are shown in Fig. 12-14. With the increase of arc current intensity, the electron temperature, electron density and arc voltage of arc plasma increase. However, it is obvious that the electron density and arc voltage of LIDTW are higher than that of LISTW, and the electron temperature is lower than that of LISTW. With the increase of laser pulse energy, the electron temperature of arc plasma decreases, while the electron density and arc voltage increase. This means that higher laser pulse energy can effectively reduce the electron temperature of arc plasma and increase the electron density. With the increase of Daa in LIDTW, the electron temperature of arc plasma increases, while the electron density and arc voltage decrease. When Daa is less than 2mm, the electron temperature of LIDTW is lower than LISTW, and the electron density and arc voltage are higher than LISTW. When Daa is larger than $2 \mathrm{~mm}$, the opposite situation appears. 

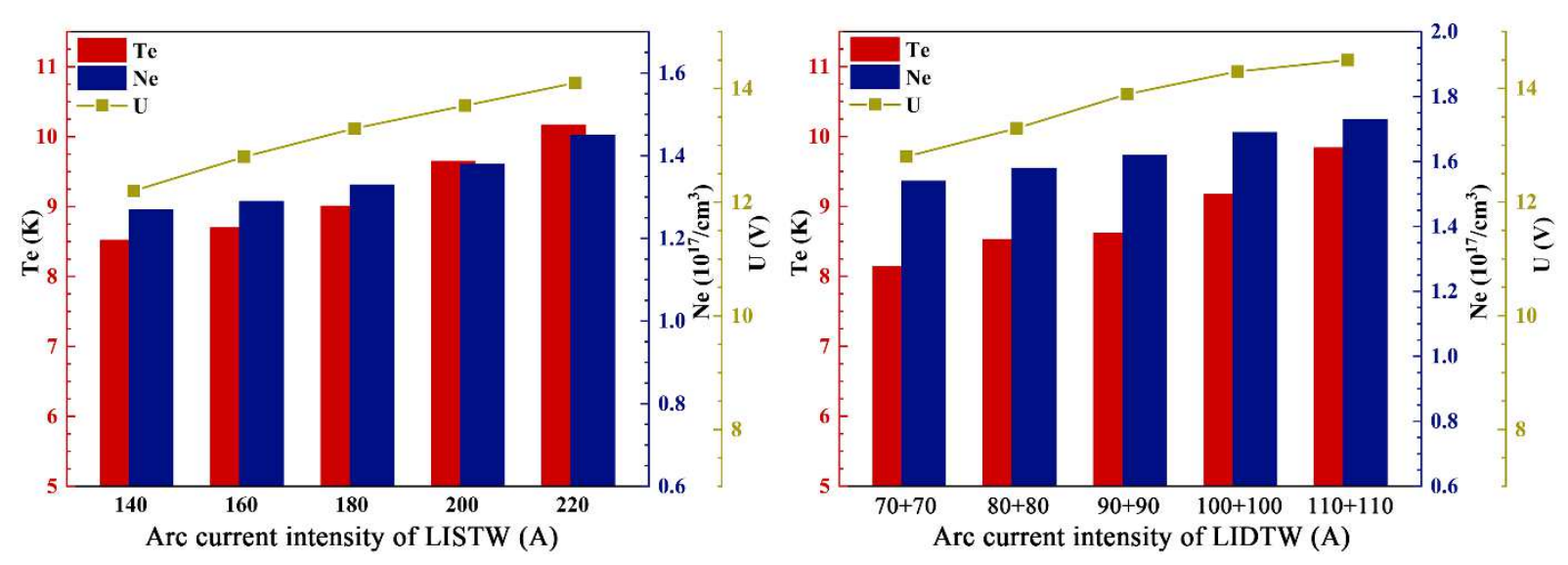

Fig. 12 Physical characteristics of plasma under different current intensity.

Welding parameters are consistent with Fig. 7.
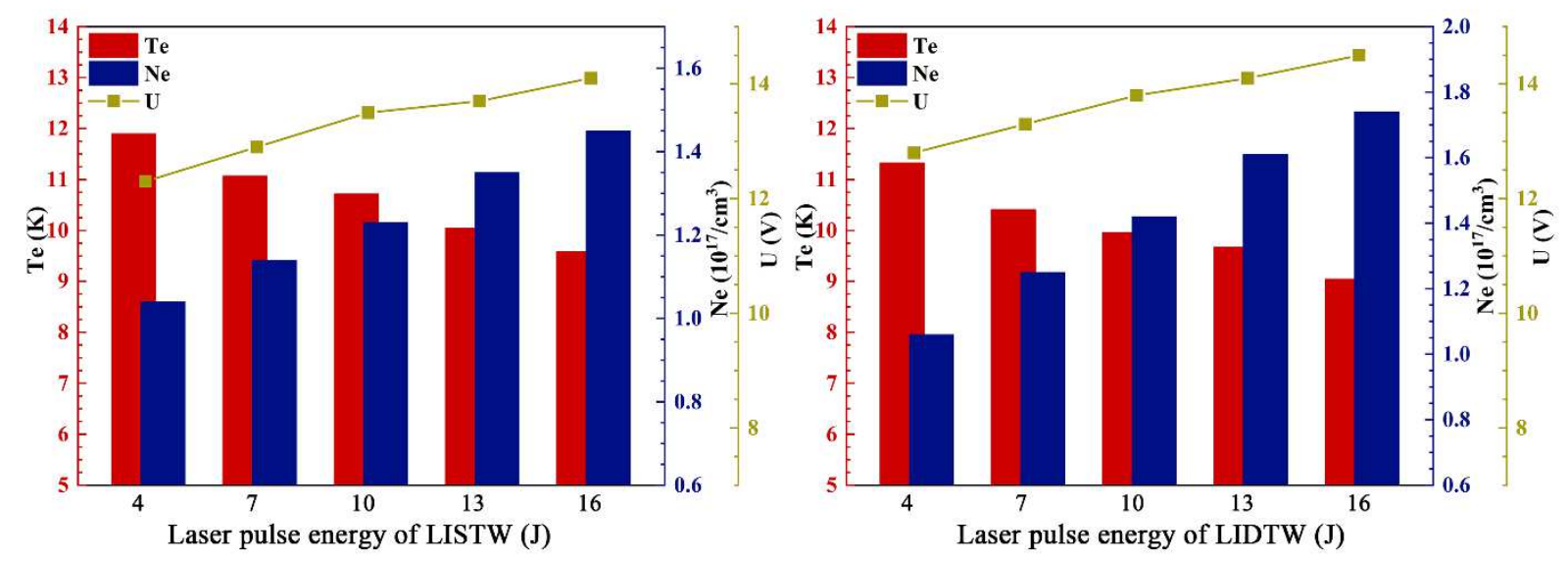

Fig. 13 Physical characteristics of plasma under different laser pulse energy. Welding parameters are consistent with Fig. 8.

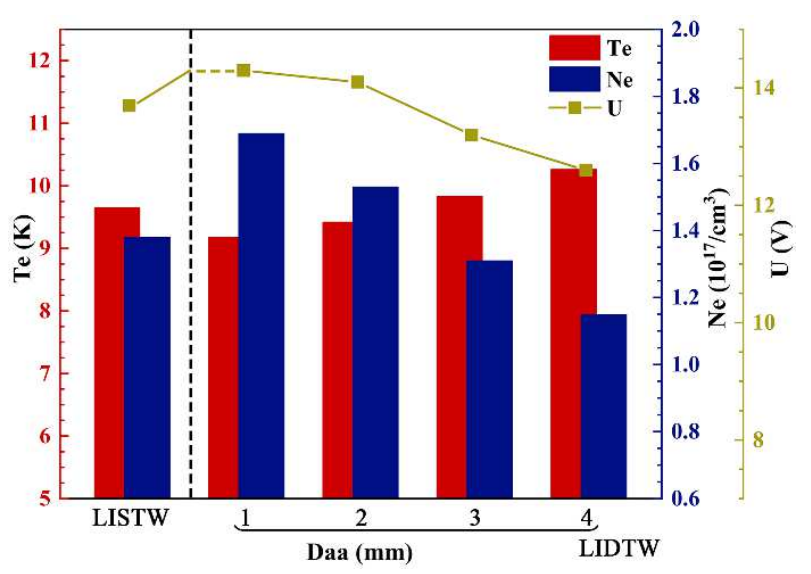

Fig. 14 Physical characteristics of plasma under different Daa.

Welding parameters are consistent with Fig. 10.

\section{Discussion}

4.1 Analysis of laser keyhole behavior 
In theory, when a laser pulse ends, the laser keyhole will begin to go through the backfill process. In fact, according to the existing research[21], when the keyhole plasma and arc plasma are coupling during the laser pulse, the arc will extend into the keyhole and connect with the keyhole plasma. The pressure of arc plasma from the keyhole on the inner wall of the keyhole hinders the collapse of the liquid metal wall. After the laser pulse action, the pressure of metal vapor will continue for a period of time due to the existence of high temperature environment in the keyhole. In addition, the coupling effect of laser and arc concentrates the arc energy into the keyhole, which increases the temperature gradient and surface tension gradient near the keyhole exit. Driven by Marangoni effect, liquid metal transfers from low surface tension region to high surface tension region. The force state of different positions in the molten pool is analyzed, as shown in Fig. 15. Under the action of force, the liquid metal in the area A of the inner wall of the keyhole flows out of the keyhole in a wavy shape (as shown in Fig. 16), which prevents the metal from backfilling into the keyhole and is conducive to maintaining the opening state of the keyhole. The time characteristics of coupling discharge are different under different welding processes. This must be related to the force state around the keyhole.

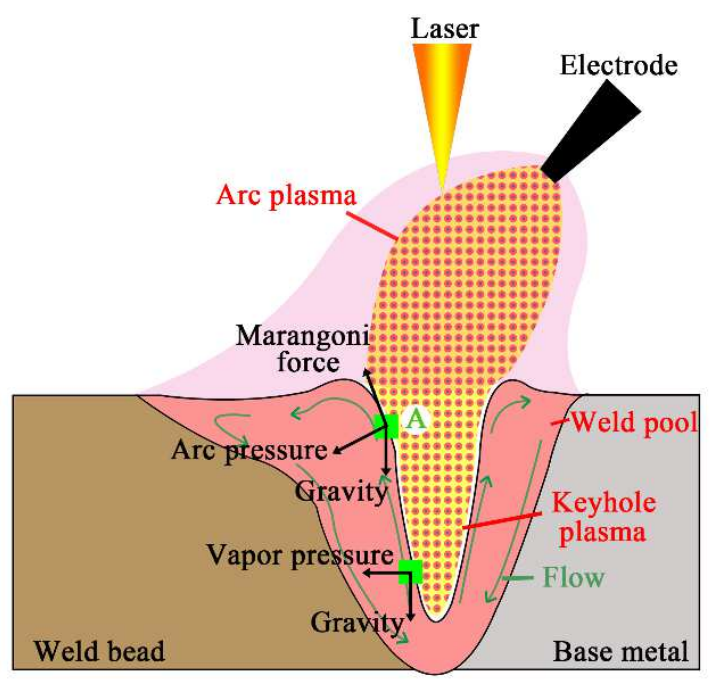

Fig. 15 Force around keyhole and molten pool flow.

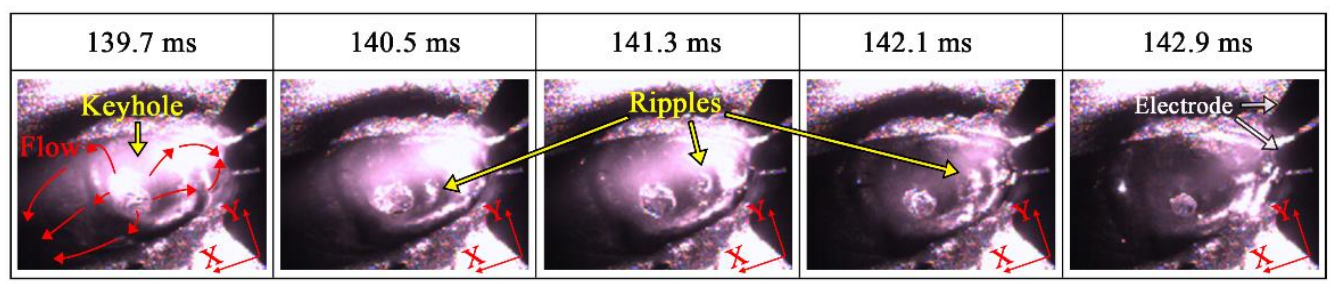

Fig. 16 Flow of liquid metal in keyhole inner wall.

\subsection{Arc pressure}

The arc pressure is the force of high-speed moving plasma jet impacting anode. Assuming that the velocity of the arc plasma reaching the anode plate is $v$, and the velocity after impacting the anode plate is 0 . According to the law of conservation of momentum, the arc pressure $P_{\text {arc }}$ can be expressed as[22]:

$$
P_{\mathrm{arc}}=\frac{1}{2} \rho v^{2}
$$

Where $\rho$ is arc plasma density.

Under the assumption of incompressible inviscid flow, the plasma velocity $v$ can be expressed as follows: 


$$
v=\sqrt{\frac{\mu_{0} I j}{2 \pi \rho}}
$$

Where $\mu_{0}$ is the permeability of the free space, $I$ is the arc current intensity and $j$ is the current density.

The arc current density $j$ can be expressed by Formula 5[23]:

$$
j=\frac{e^{2} n_{e} \lambda_{e} E}{\sqrt{8 m_{e} k T_{e} / \pi}}
$$

Where $j$ is the current density, $e$ is the electron charge, $n_{e}$ is the electron density of arc plasma, $\lambda_{e}$ is the electron mean free path, $E$ is the electric field strength, $m_{e}$ is the electron mass, $k$ is Boltzmann constant, $T_{e}$ is the electron temperature of arc plasma.

Combined with the above three formulas, the arc pressure $P_{\text {arc }}$ can be described as follows:

$$
P_{\mathrm{arc}}=\frac{0.05 \mu_{0} e^{2} \lambda_{e}}{\sqrt{m_{e} k T_{e}}} \operatorname{In} n_{e} E
$$

This formula shows that $P_{\text {arc }}$ has a weak correlation with $T_{e}$, but has a strong correlation with $I, n_{e}$ and $E$. If $I, n_{e}$ and $E$ increase, $P_{\text {arc }}$ will also increase.

As shown in the experimental results in Section 3.2, the first thing that can be noticed is that LIDTW has a larger the duty ratio of coupling discharge than LISTW when all experimental parameters (current intensity, laser energy, welding speed, etc.) are the same. It can be seen from the experimental results in Section 3.3 that $n_{e}$ and $E$ of LIDTW under the same conditions, so $P_{\text {arc }}$ is also larger. The backfilling behavior of liquid metal is restrained. This difference may be related to the driving force of laser induced arc discharge. According to the reference[20], when the induced driving force of laser on arc overcomes the stiffness of arc, the induced discharge phenomenon occurs in hybrid welding. And the greater the induced driving force is, the greater the compression degree of the arc conduction channel is. In LISTW and LIDTW, the induced driving force of laser to arc can be described by Formula 7 and 8 respectively:

$$
\begin{gathered}
\vec{F}_{\text {LISTW }}=\frac{\mu}{4 \pi} \int_{0}^{h} \int_{0}^{s} \frac{\vec{I}_{k} d l_{k} \times \vec{I}_{a} d l_{a}}{d} \\
\vec{F}_{\text {LIDTW }}=\frac{\mu}{4 \pi}\left(\int_{0}^{h} \int_{0}^{s} \frac{\vec{I}_{k} d l_{k} \times \vec{I}_{a} d l_{a}}{d}+\int_{0}^{s} \frac{\left(\vec{I}_{a} d l_{a}\right)^{2}}{2 d}\right)
\end{gathered}
$$

Where $h$ is the keyhole depth, $s$ is the arc length, $I_{k}$ is the keyhole current intensity, $I_{a}$ is the arc current intensity, $d$ is the distance between arc current and keyhole current.

It can be found that plasma in LIDTW is not only attracted by keyhole current, but also has electromagnetic attraction between arc currents in the same direction. $\vec{F}_{\text {LIDTW }}$ is greater than $\vec{F}_{\text {LISTW }}$. As an inherent property of plasma to resist external interference and prevent its shape and direction from changing, arc stiffness is directly proportional to arc current intensity. When a large arc current is divided into two small arc currents, the arc stiffness decreases, and the resistance to change the discharge position of arc plasma decreases. Therefore, the diameter of arc conductive channel in LIDTW is greatly reduced, and the arc voltage increases according to the principle of minimum voltage. The contraction of conductive channel intensifies the coupling enhancement of double-arc electromagnetic field. Driven by the electric field force and Lorentz force in the coupling field, the electron accelerates and obtains a lot of energy. The intense collision between high-energy electrons and heavy particles promotes the ionization of heavy particles, resulting in the obvious increase of plasma electron density. Under the action of large arc pressure, the existence time of laser keyhole is prolonged and the duty ratio of coupling discharge is increased.

It can be seen from Formula 7-8 that the induced driving force $\vec{F}$ of laser on arc is directly proportional to the depth and current of laser keyhole. Therefore, when the laser pulse energy increases, $\vec{F}$ increases, the conductive channel of the arc shrinks and the electron density increases. In addition, in hybrid welding, large laser energy will 
increase the number of $\mathrm{Mg}$ atoms migrating from the keyhole into the arc plasma, thereby increasing the electron density of the plasma. When more charged particles pass through a smaller section, the resistivity increases. To keep the current intensity unchanged, the arc voltage increases. According to Formula 6 , the increase of $P_{\text {arc }}$ hinders the collapse of liquid metal wall in the keyhole, resulting in the increase of coupling discharge duty ratio with the increase of pulse energy. However, increasing the current intensity will also increase the $I, n_{e}$ and $E$ of arc plasma, resulting in $P_{\text {arc }}$ increases, but the coupling discharge duty ratio of LISTW and LIDTW decreases gradually. This shows that the laser keyhole behavior is not only related to the arc pressure.

\subsection{Marangoni force}

Marangoni force is caused by surface tension gradient, which has a great influence on promoting metal flow in molten pool[24, 25]. The pulsed laser attracts the arc plasma to discharge in the keyhole, so the temperature gradient and surface tension gradient are generated in the outlet area of the keyhole. The Marangoni force acting on the keyhole wall can be described as[26]:

$$
F_{\mathrm{m}}=\frac{\partial \gamma}{\partial T} \frac{\partial T}{\partial r}
$$

Where $F_{\mathrm{m}}$ is Marangoni force, $\partial \gamma / \partial T$ is the surface tension gradient, $\partial T / \partial r$ is the temperature gradient. It can be seen that Marangoni force is directly proportional to the surface tension gradient. Large surface tension gradient leads to the increase of Marangoni force, which promotes the liquid metal to flow out of the keyhole and inhibits the backfilling behavior of the keyhole.

The discharge position of arc root in LISTW and LIDTW under different arc current intensity is shown in Fig. 17. When the current intensity is small and the laser keyhole can carry all the arc current, the arc conductive channel fully extends into the keyhole. At this time, the anode spot is not on the surface of the molten pool, but in an uncertain discharge area on the inner wall of the keyhole. The heat input to the surface of the molten pool is limited, resulting in the lower temperature of the molten pool surface relative to the inner wall of the keyhole. A large surface tension gradient is generated in the outlet area of the keyhole. Under the action of large Marangoni force, the backfilling behavior of laser keyhole is inhibited, which increases the duty ratio of coupling discharge. With the increase of current intensity, the diameter of arc conductive channel becomes larger. Due to the limitation of keyhole size, the keyhole can not fully carry arc current. The arc plasma discharges not only with the inner wall of the keyhole, but also with the surface of the molten pool around the keyhole. The metal temperature on the surface of the molten pool increases, resulting in the decrease of surface tension, which reduces the surface tension gradient and Marangoni force in the outlet area of the keyhole, and the driving force of liquid metal flowing out of the keyhole is weakened. In addition, the decrease of surface tension increases the fluidity of molten pool metal, the backfilling speed of keyhole is accelerated, and the duty ratio of coupling discharge is reduced. Therefore, the increase of arc current intensity has a negative effect on the time characteristics of coupling discharge of heat source.

In addition, at the same current intensity, LIDTW has a smaller conductive channel diameter than LISTW due to the difference of induced driving force. In other words, the laser keyhole in LIDTW process can carry greater arc current intensity. This can well explain the experimental results in section 3.2.1. The difference of arc conduction channel diameter leads to the difference of surface tension gradient $(\partial \gamma / \partial T)$ at the outlet of keyhole. The surface tension gradient is greater resulting from the smaller diameter of the conductive channel, resulting in the greater Marangoni force. In LIDTW process, large arc pressure and Marangoni force jointly drive the liquid metal to flow out of the keyhole against gravity, prolonging the existence time of the keyhole and increasing the duty ratio of coupling discharge. 


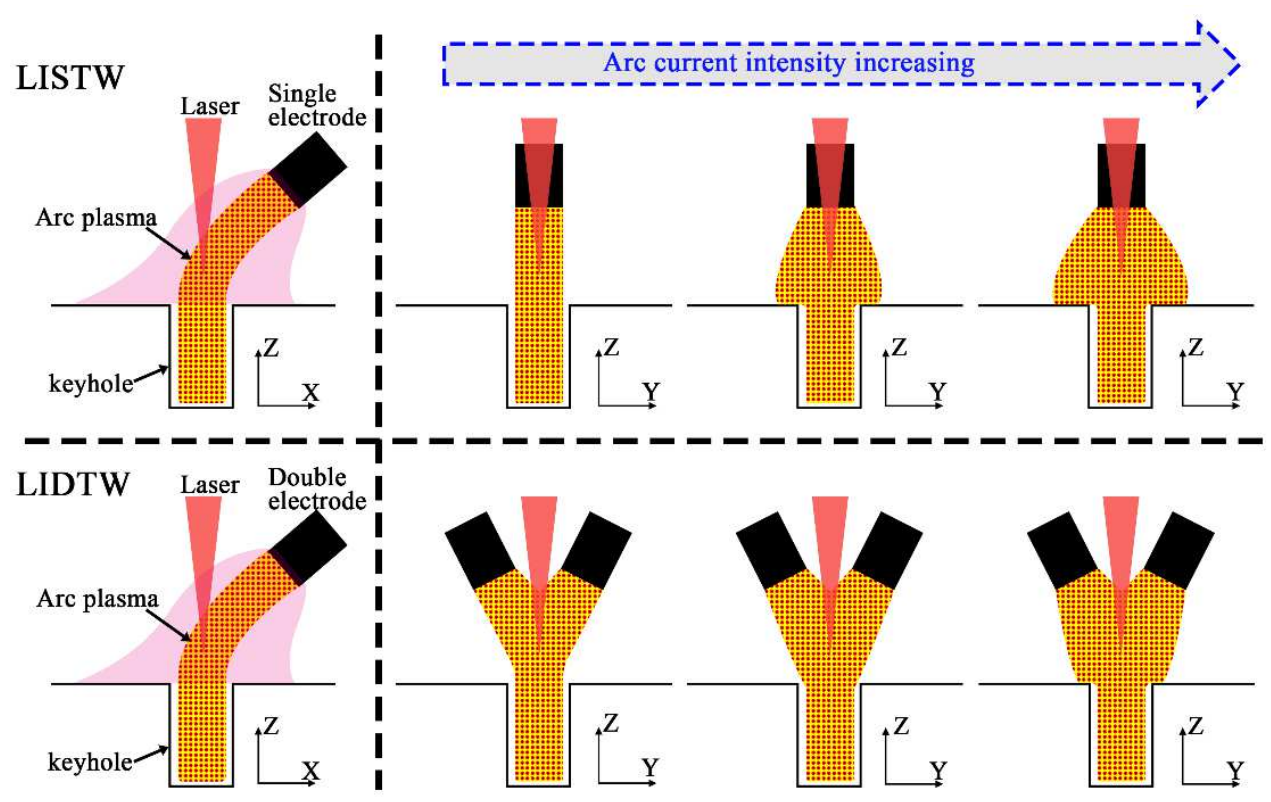

Fig. 17 Discharge position of arc root under different current intensity.

With the increase of Daa, the duty ratio of coupling discharge in LIDTW gradually decreases. On the one hand, according to Formula 8, the increase of Daa reduces the induced driving force of laser on arc plasma, which makes the coupling discharge between laser and arc more difficult, and the electron density and arc voltage of arc plasma decrease accordingly. The arc pressure acting on the inner wall of the keyhole decreases, and the resistance to prevent the liquid metal from flowing back into the keyhole decreases; On the other hand, the increasing Daa also leads to a larger arc conductive channel diameter (Fig. 18), and the heating area of the molten pool surface increases, which reduces the temperature gradient and surface tension gradient near the keyhole outlet, resulting in the decrease of Marangoni force. The gravity of liquid metal accelerates the backfilling of keyhole.

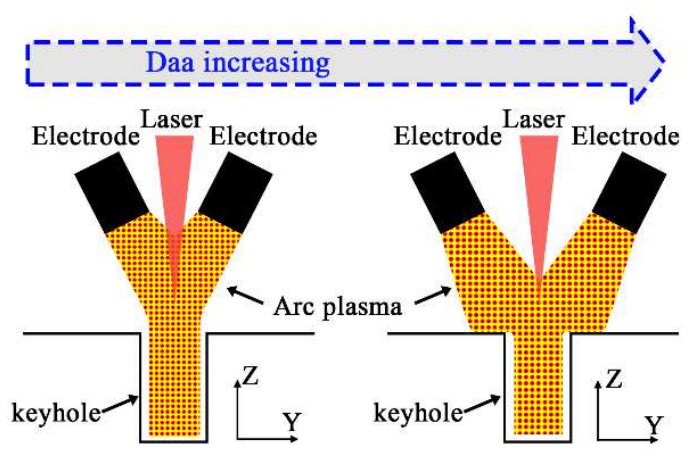

Fig. 18 Discharge position of arc root under different Daa.

\section{Conclusion}

The time characteristics of coupling discharge in low power pulsed laser induced double-arc welding (LIDTW) are studied in this paper. The effects of welding parameters on the time characteristics of coupling discharge and the physical characteristics of arc plasma are analyzed, and the physical model is established to reveal the regulation mechanism of the time characteristics of coupling discharge. The following conclusions are drawn:

(1) The time characteristics of coupling discharge in laser induced arc welding are related to the dynamic behavior of laser keyhole. The longer the keyhole exists, the greater the duty ratio of the coupling discharge of the heat sources is. When the total current intensity is $200 \mathrm{~A}$, compared with LISTW, the keyhole existence time of 
LIDTW is prolonged by $77 \%$, the duty ratio of coupling discharge is increased by $12 \%$, and the welding penetration is increased by $29.2 \%$.

(2) The difference of physical characteristics of arc plasma between LISTW and LIDTW is related to the induced driving force and driving resistance of laser to arc. Compared with LISTW, the relatively large induced driving force and small driving resistance in LIDTW promote the reduction of arc conductive channel diameter and the coupling enhancement of double-arc electromagnetic field, and improve the electron density of plasma and arc voltage.

(3) In hybrid welding, the electron density of plasma and arc voltage are directly proportional to current intensity and laser pulse energy, and inversely proportional to Daa (the distance between two electrodes in LIDTW). The surface tension gradient of liquid metal is related to the diameter of arc conductive channel, which is directly proportional to the laser pulse energy and inversely proportional to the arc current intensity and Daa.

(4) During hybrid welding, when the combined force of arc pressure and Marangoni force can overcome gravity, the liquid metal is forced to flow out of the keyhole to prevent the backfilling of the keyhole. Improving the electron density of plasma and arc voltage and reducing the diameter of arc conductive channel by selecting appropriate parameters are conducive to the stable existence of keyhole, increasing the coupling discharge time and improving the welding penetration.

\section{Declarations:}

a. Funding: This work was supported by the National Key R\&D Program of China (2018YFB1107902) organization name: Ministry of Science and Technology of the People's Republic of China.

b. Conflicts of interest/Competing interests: The authors declare that they have no known competing financial interests or personal relationships.

c. Availability of data and material: All the data have been presented in the manuscript.

d. Code availability: (Not applicable).

e. Ethics approval: The paper follows the guidelines of the Committee on Publication Ethics (COPE).

f. Consent to participate: The authors declare that they all consent to participate this research.

g. Consent for publication: The authors declare that they all consent to publish the manuscript.

\section{h. Authors' contributions}

Xinkun Xu（徐信坤）: Roles/Writing - original draft; Methodology; Formal analysis;

Huanyu Yang（杨环宇）: Data curation; Supervision; Validation;

Liming Liu（刘黎明）: Conceptualization; Funding acquisition; Writing - review \& editing;

\section{References:}

[1] Steen W (1980) Arc augmented laser processing of materials. J Appl Phys 51(11): 5636-5641.

[2] Gao Z, Wu Y, Huang J (2009) Analysis of weld pool dynamic during stationary laser-MIG hybrid welding. Int J Adv Manuf Tech 44(9-10): 870-879.

[3] Jiang F, Wang S, Xu B, Cheng W, Ma X, Chen S (2021) Local energy adjustment mechanism in a novel laserenhanced plasma arc heat source. International Journal of Thermal Sciences 168.

[4] Ragavendran M, Chandrasekhar N, Ravikumar R, Saxena R, Vasudevan M, Bhaduri A K (2017) Optimization of hybrid laser-TIG welding of 316LN steel using response surface methodology (RSM). Opt Laser Eng 94: 27-36. [5] Wieschemann A, Keller H, Dilthey U (2003) Hybrid-welding and the HyDra MAG+Laser processes in shipbuilding. Welding International 17(10): 761-766.

[6] Qin G, Meng X, Fu B (2015) High speed tandem gas tungsten arc welding process of thin stainless steel plate. J Mater Process Tech 220: 58-64. 
[7] Scalet Rossini L F, Valenzuela Reyes R A, Spinelli J E (2019) Double-wire tandem GMAW welding process of HSLA50 steel. J Manuf Process 45: 227-233.

[8] Gu X, Li H, Jiang X, Sheng H, Wan X (2016) Effect of laser on droplet transfer and welding process stability in hybrid laser + double arc welding. Int J Adv Manuf Tech 89(9-12): 2981-2991.

[9] Wei H L, Li H, Yang L J, Gao Y, Ding X P (2015) Arc characteristics and metal transfer process of hybrid laser double GMA welding. Int J Adv Manuf Tech 77: 1019-1028.

[10] Hu L, Huang J, Liu C, Liu X, Hou D, Xu C, Zhao Y (2018) Effects of coupling between the laser plasma and two arcs on metal transfer in CO2 laser double-wire MIG hybrid welding. Opt Laser Technol 105: 152-161.

[11] Gu X, Li H, Yang L, Gao Y (2013) Coupling mechanism of laser and arcs of laser-twin-arc hybrid welding and its effect on welding process. Opt Laser Technol 48: 246-253.

[12] Liu L, Hao X (2008) Study of the effect of low-power pulse laser on arc plasma and magnesium alloy target in hybrid welding by spectral diagnosis technique. J Phys D Appl Phys 41(20).

[13] Xu G X, Wu C S, Qin G L, Wang X Y, Lin S Y (2011) Adaptive volumetric heat source models for laser beam and laser-pulsed GMAW hybrid welding processes. Int J Adv Manuf Tech 57: 245-255.

[14] Hu B, Ouden G (2005) Laser induced stabilisation of the welding arc. Sci Technol Weld Joi 10: 76-81.

[15] Zhan X H, Chen J C, Liu J J, Wei Y H, Zhou J, Meng Y (2016) Microstructure and magnesium burning loss behavior of AA6061 electron beam welding joints. Mater Design 99: 449-458.

[16] Liu L, Chen M (2011) Interactions between laser and arc plasma during laser-arc hybrid welding of magnesium alloy. Opt Laser Eng 49(9-10): 1224-1231.

[17] Sabbaghzadeh J, Dadras S, Torkamany M J (2007) Comparison of pulsed Nd : YAG laser welding qualitative features with plasma plume thermal characteristics. J Phys D Appl Phys 40(4): 1047-1051.

[18] (2019) National Institute of Standards and Technology database. https://www.nist.gov/pml/atomic-spectradatabase Accessed 25 December 2019.

[19] Griem H (1974) Spectral line broadening by plasma. Academic Press, New York.

[20] Liu L, Xu X, Zhu Y (2020) Study on synchronous induction of arc plasma by laser in laser-double TIG hybrid welding. Opt Laser Eng 133.

[21] Liu L, Chen M, Li C (2013) Effect of electric arc on laser keyhole behavior based on direct observation during low power pulsed laser-arc hybrid welding process. Opt Laser Eng 51(10): 1153-1160.

[22] Leng X, Zhang G, Wu L (2006) The characteristic of twin-electrode TIG coupling arc pressure. J Phys D Appl Phys 39(6): 1120-1126.

[23] AnTeng H, ChangGu C (1985) Welding arc phenomenon. Machinery Industry Press.

[24] Wang X, Luo Y, Fan D (2019) Investigation of heat transfer and fluid flow in high current GTA welding by a unified model. International Journal of Thermal Sciences 142: 20-29.

[25] Abderrazak K, Kriaa W, Ben Salem W, Mhiri H, Lepalec G, Autric M (2009) Numerical and experimental studies of molten pool formation during an interaction of a pulse laser (Nd:YAG) with a magnesium alloy. Opt Laser Technol 41(4): 470-480.

[26] Ai Y, Liu X, Huang Y, Yu L (2020) Numerical analysis of the influence of molten pool instability on the weld formation during the high speed fiber laser welding. International Journal of Heat and Mass Transfer 160. 